UDC 519.6

\title{
BI-HAMILTONIAN STRUCTURE AND EXACT SOLUTIONS OF ONE BURGERS' TYPE NONLINEAR DYNAMICAL SYSTEM
}

\author{
I. Mykhailiuk ${ }^{1}$, M. Prytula ${ }^{2}$ \\ Ivan Franko National University of Lviv, \\ Universytetska str., 1, Lviv, 79000, \\ e-mail: ${ }^{1}$ iv.mykh@gmail.com, ${ }^{2}$ mykola.prytula@gmail.com
}

\begin{abstract}
Bi-Hamiltonian systems play an important role in the study of completely integrable nonlinear dynamical systems. In the present work, we find the bi-Hamiltonian representation as well as three classes of exact solutions for one Burgers' type three-component nonlinear dynamical system, which arises in the context of a dispersionful version of the so-called universal Whitham hierarchy. We begin with some important definitions from the theory of completely integrable nonlinear dynamical systems, namely those of conservation law and its gradient and bi-Hamiltonian representation of a system. After that, for the above-mentioned dynamical system, we construct the infinite hierarchy of functionally independent conservation laws utilizing the gradient holonomic method. Moreover, based on that hierarchy we find the implectic pair of Noetherian operators and corresponding Hamiltonian functionals applying the differential-algebraic algorithm. Furthermore, we construct three classes of exact traveling wave solutions, in particular, solitary wave and periodic ones, using the $\left(\mathrm{G}^{\prime} / \mathrm{G}\right)$-expansion method. It is shown that for the case of the dynamical system under consideration, the degrees of polynomials in $\left(G^{\prime} / G\right)$ cannot be uniquely determined from the system of algebraic equations of the homogeneous balance. Nevertheless, utilizing a more detailed analysis, a general form of the solution is found uniquely. Further, we analyze the obtained results, in particular, the analytical solution is verified by putting it back into the original equations. Finally, we anticipate future research objectives, especially finding the standard Lax type representation of the above-mentioned dynamical system.

Key words: nonlinear dynamical system, conservation law, implectic operator, Hamiltonian functional, exact solution, solitary wave, gradient holonomic method, (G'/G)-expansion method.
\end{abstract}

\section{INTRODUCTION}

Since the middle of the 20th century, nonlinear dynamical systems (NDS) have been the object of intensive research. This is, on the one hand, due to their crucial importance in physics, biology, and other natural sciences and, on the other hand, due to the discovery of soliton by N.Zabusky and M. Kruskal [20] which completely changed the perception of nonlinear dynamics.

One of the key theoretical notions in the context of nonlinear dynamical systems is that of complete integrability. There is a number of formal definitions of the integrable dynamical system. For instance, in the case of Hamiltonian systems, there is a concept of complete integrability in the Liouville sense [3,12] which is formalized in the LiouvilleArnold theorem [1]. In any case, three generally recognizable features [5] of completely integrable systems are the following:

- existence of many conserved quantities;

- presence of algebraic geometry;

- ability to give explicit solutions.

(C) Mykhailiuk I., Prytula M., 2020 
The above-mentioned features of integrable dynamical systems have been extensively investigated in the literature since the 1960s. The modern theory dates back to the articles by Lax [9], Gardner et al. [11], and others, in which the inverse scattering transform method for the Korteweg - de Vries equation was introduced. This method, which is used to solve initial and/or boundary value problems for completely integrable nonlinear dynamical systems, was further extended by Zakharov, Shabat and other to a new class of dynamical systems (see [16] and references therein). On the other hand, Magri [10] introduced a very important notion of bi-Hamiltonian systems which gave rise to the concept of the complete integrability in the Liouville sense $[1,12]$.

Later on, Ablowitz et al. [15] introduced a regular procedure for the construction of new completely integrable in the Lax sense nonlinear evolution equations as well as their explicit soliton solutions. Besides that, M. Bogoliubov (Jr.), A. Prykarpatskyi and their students (see [3] and references therein) developed an efficient method of obtaining integrability criteria for nonlinear dynamical systems on functional manifolds called the gradient holonomic method.

On the other hand, a lot of attention has been paid to the problem of finding exact solutions of nonlinear dynamical systems. The above-mentioned inverse scattering transform method is undoubtedly the most important discovery in this area of research [16]. When applicable, it leads to wide classes of solutions for completely integrable systems [14]. Nevertheless, in practice, the calculations are very complicated.

Alternatively, one can utilize a partial method (ansatz) to find the solution of a nonlinear evolution equation (NEE) of some particular shape. Over the last decades, numerous techniques to construct abundant classes of solutions, in particular, the traveling wave ones, have been developed. Some of the well-known methods include the Painlevé expansion method [19], the Hirota bilinear method [4], the homogeneous balance method [17], the tanh method [2], the Jacobi elliptic function method [7], and the $\left(\frac{G^{\prime}}{G}\right)$ - expansion method [18].

Nowadays, the most important problems of the theory of completely integrable dynamical systems, among others, are the following [3]:

1. classification of nonlinear dynamical systems, i.e. the construction of integrability criteria;

2. extension of the class of completely integrable systems;

3. construction of exact solutions (in particular, the soliton ones);

4. study of differential-geometric, algebraic and Hamiltonian properties of nonlinear dynamical systems, etc.

In the present work, we address the second and the third problems in the list above in application to the following dispersionful (Burgers' type) nonlinear dynamical system:

$$
\left\{\begin{array}{l}
u_{t}=2 a_{x} \\
a_{t}=\left(a_{x}+2 a q\right)_{x} \\
q_{t}=\left(-q_{x}+q^{2}+u\right)_{x}
\end{array}\right.
$$

Eqs. (1) were introduced by Szablikowski et al. [13] as the authors constructed a dispersionful version of the so-called universal Whitham hierarchies by means of moduli spaces of Riemann surfaces of all genera.

The remainder of this article is organized as follows. In Section 2 we give some basic theoretical notions related to the bi-Hamiltonian analysis of nonlinear dynamical 
Mykhailiuk I., Prytula M.

ISSN 2078-5097. Вісн. Львів. ун-ту. Сер. прикл. матем. та інф. 2020. Вип. 28

systems. Furthermore, based on the gradient holonomic method [3] and differentialalgebraic algorithm [8,12] we construct the infinite hierarchy of conservation laws and find the implectic pair of Noetherian operators for Eqs. (1). In Section 3 we find three classes of exact solutions of Eqs. (1) utilizing the $\left(\frac{G^{\prime}}{G}\right)$ - expansion method [18]. Finally, in Section 4 we summarize our findings and outline prospects for future research.

\section{Bi-Hamiltonian Structure}

Based on $[3,6,8,12]$ let us give some basic theoretical foundation for our further analysis.

Assume that a generic nonlinear dynamical system is locally written as a partial differential equation (PDE)

$$
u_{t}=K[u], u \in M,
$$

where $M$ is an infinite-dimensional smooth functional manifold, $T(M)$ is the tangent bundle over $M, K: M \rightarrow T(M)$ is a Frechét smooth local functional which, in general, is represented as $K[u]=K\left(u, u_{x}, u_{x x}, \ldots, u_{n x}\right)$, where $u_{n x}=\frac{\partial^{n} u}{\partial x^{n}}$.

Definition 5. A functional

$$
\gamma[u]:=\int_{x_{0}}^{x_{0}+l} \sigma[u] d x \in D(M)
$$

is called a conservation law for system (2) if it does not change along the trajectory of the vector field, i.e.

$$
\left.\frac{d \gamma[u]}{d t}\right|_{K[u]} \equiv 0
$$

where $u \in M, \sigma[u]$ is a local functional, $D(M)$ is a space of Fréchet smooth functionals on $M$.

The standard bilinear form on the domain $U=\left\{x \in \mathbb{R}: x_{0} \leq x \leq x_{0}+l\right\}$ is defined as

$$
(a, b)=\int_{U}\langle a, b\rangle d x
$$

where $a, b \in C_{0}^{\infty}\left(U, \mathbb{R}^{n}\right)$. Eq. (5) defines the structure of the Hilbert space on the tangent space $T(M) \cong T^{*}(M)$.

Definition 6. The gradient of the conservation law $\gamma[u] \in D(M)$ is defined as

$$
\operatorname{grad} \gamma[u]=\frac{\delta \gamma[u]}{\delta u}=\left((\sigma[u])^{\prime}\right)^{*} \cdot 1
$$

where "*" denotes the adjoint operator w.r.t. the standard bilinear form (5).

Definition 7. Dynamical system (2) is bi-Hamiltonian if it can be represented as

$$
u_{t}=-\vartheta \operatorname{grad} H_{\vartheta}=-\eta \operatorname{grad} H_{\eta}=K[u],
$$

where $H_{\vartheta}, H_{\eta}$ are Hamiltonian functionals; $\vartheta, \eta: T^{*}(M) \rightarrow T(M)$ is the pair of implectic operators.

To find the implectic pair of Noetherian operators for Eq. (2) we apply the differentialalgebraic algorithm which consists of the following steps. 
If the conservation law $\gamma[u]$ can be represented as

$$
\gamma[u]=\int_{x_{0}}^{x_{0}+l} \tilde{\sigma}[u] d x=\int_{x_{0}}^{x_{0}+l}\left\langle\sigma[u], u_{x}\right\rangle d x
$$

then the functional $\sigma[u]$ is used to construct the symplectic operator

$$
\theta^{-1}=\sigma^{\prime}-\sigma^{*}
$$

Further, if the inverse of $\theta^{-1}$ exists, then $\theta$ is the implectic operator.

For a general $n$-component dynamical system, we have

$$
\begin{gathered}
\gamma[u]=\int_{x_{0}}^{x_{0}+l}\left(\left\langle\sigma_{1}[u], u_{1, x}\right\rangle+\cdots+\left\langle\sigma_{n}[u], u_{n, x}\right\rangle\right) d x \\
\sigma^{\prime}=\left(\begin{array}{ccc}
\frac{\partial \bar{\sigma}_{1}}{\partial u_{1}} & \cdots & \frac{\partial \bar{\sigma}_{1}}{\partial u_{n}} \\
\vdots & & \vdots \\
\frac{\partial \bar{\sigma}_{n}}{\partial u_{1}} & \cdots & \frac{\partial \bar{\sigma}_{n}}{\partial u_{n}}
\end{array}\right) .
\end{gathered}
$$

Finally, to facilitate our further analysis let us rewrite Eqs. (1) in the following way:

$$
w_{t}=\left(\begin{array}{l}
u \\
a \\
q
\end{array}\right)_{t}=\left(\begin{array}{c}
2 a \\
a_{x}+2 a q \\
-q_{x}+q^{2}+u_{x}
\end{array}\right)_{x}=K[w]=K[u, a, q],
$$

where $K: M \rightarrow T(M)$ is a Fréchet smooth polynomial vector field which is defined on the infinite dimensional functional manifold $M=C_{l}^{\infty}\left(\mathbb{R}^{1} ; \mathbb{R}^{3}\right), \mathbb{R}_{+}^{1} \ni l<\infty$ is a period, and $t \in \mathbb{R}^{1}$ is the evolution parameter.

\subsection{Conservation LaWs}

In order to find the infinite hierarchy of conservation laws for Eq. (12), consider the asymptotic solution of the linear Lax equation

$$
\phi_{t}+K^{\prime *} \phi=0
$$

where $\phi \in T^{*}(M)$, the prime symbol, "'", denotes the Fréchet derivative of the nonlinear local functional $K[u, a, q]$, and the asterisk symbol, "**, denotes the adjunction w.r.t. the standard bilinear form (5).

Firstly, from the representation (12) we obtain the explicit formula for the operator $K^{\prime}$ as follows:

$$
K^{\prime}=\left(\begin{array}{ccc}
0 & 2 \partial & 0 \\
0 & \partial^{2}+2 \partial q & 2 \partial a \\
\partial & 0 & -\partial^{2}+2 \partial q
\end{array}\right)
$$

Hence, the operator $K^{\prime *}: T^{*}(M) \rightarrow T^{*}(M)$ has the following form:

$$
K^{\prime *}=\left(\begin{array}{ccc}
0 & 0 & -\partial \\
-2 \partial & \partial^{2}-2 q \partial & 0 \\
0 & -2 a \partial & -\partial^{2}-2 q \partial
\end{array}\right) \text {. }
$$


Mykhailiuk I., Prytula M.

Furthermore, Eq. (13) admits a vector solution of the form

$$
\phi(x, t ; \lambda)=\left(\begin{array}{c}
1 \\
b(x, t ; \lambda) \\
c(x, t ; \lambda)
\end{array}\right) \exp \left[\lambda x+\omega(\lambda) t+\partial^{-1} \sigma(x ; \lambda)\right]
$$

where $\lambda \in \mathbb{C}^{1}$ is a parameter, $\partial^{-1}(\cdot)=\frac{1}{2}\left[\int_{x_{0}}^{x}(\cdot) d x-\int_{x}^{x_{0}+l}(\cdot) d x\right]$ is the inverse differentiation operator (i.e. $\partial \cdot \partial^{-1}=1$ ), and $x_{0}$ is an arbitrary fixed point.

In order to find the dispersion relation $\omega(\lambda)$ in Eq. (16), we need to solve Eq. (13) at the point $u=0, a=0, q=0$, i.e.

$$
\phi_{t}+\left(\begin{array}{ccc}
0 & 0 & -\partial \\
-2 \partial & \partial^{2} & 0 \\
0 & 0 & -\partial^{2}
\end{array}\right) \phi=0
$$

Taking into account the representation (16) and solving Eq. (17) we obtain $b=\lambda^{-1}, c=$ $\lambda, \omega=\lambda^{2}$.

Going back to Eq. (13) and its solution (16), we have that the following asymptotic expansions as $\lambda \rightarrow \infty$ hold:

$$
\begin{aligned}
b(x, t ; \lambda) & \simeq \sum_{j=1}^{\infty} b_{j}[u, a, q] \lambda^{-j}, \\
c(x, t ; \lambda) & \simeq \sum_{j=-1}^{\infty} c_{j}[u, a, q] \lambda^{-j}, \\
\sigma(x, t ; \lambda) & \simeq \sum_{j=-1}^{\infty} \sigma_{j}[u, a, q] \lambda^{-j} .
\end{aligned}
$$

Substituting the sought-after solution (16), taking into account relations (18), into Eq. (13) we obtain the infinite system of recurrence equations of the form

$$
\begin{gathered}
\delta_{j,-2}+\partial^{-1} \sigma_{j, t}-c_{j, x}-c_{j+1}-\sum_{k} c_{j-k} \sigma_{k}=0 \\
b_{j, t}+\sum_{k} b_{j-k} c_{k, x}+\sum_{k} b_{j+1-k} c_{k}+\sum_{k, s} b_{j-k} c_{k-s} \sigma_{s}-2 \delta_{j,-1}-2 \sigma_{j}+ \\
+b_{j, x x}+2 b_{j+1, x}+2 \sum_{k} b_{j-k, x} \sigma_{k}+\sum_{k} b_{j-k} \sigma_{k, x}+2 \sum_{k} b_{j+1-k} \sigma_{k}+ \\
+b_{j+2}+\sum_{k, s} b_{j-k} \sigma_{k-s} \sigma_{s}-2 q b_{j, x}-2 q b_{j+1}-2 q \sum_{k} b_{j-k} \sigma_{k}=0 \\
c_{j, t}+\sum_{k} c_{j-k} c_{k, x}+\sum_{k} c_{j+1-k} c_{k}+\sum_{k, s} c_{j-k} c_{k-s} \sigma_{s}-2 a b_{j, x}-2 a b_{j+1}+ \\
-2 a \sum_{k} b_{j-k} \sigma_{k}-c_{j, x x}-2 c_{j+1, x}-2 \sum_{k} c_{j-k, x} \sigma_{k}-\sum_{k} c_{j-k} \sigma_{k, x}-c_{j+2}+ \\
-2 \sum_{k} c_{j+1-k} \sigma_{k}-\sum_{k, s} c_{j-k} \sigma_{k-s} \sigma_{s}-2 q c_{j, x}-2 q c_{j+1}-2 q \sum_{k} c_{j-k} \sigma_{k}=0 .
\end{gathered}
$$

In the equations above, $j \in \mathbb{Z}, \delta$ is the Kronecker delta. 
Successively solving Eqs. (19)-(21) we can find explicit formulae for local functionals $\sigma(x, t ; \lambda)$. In particular, first six of them have the following form:

$$
\begin{gathered}
b_{-1}=0, \quad b_{0}=0, \\
c_{-1}=1, \quad c_{0}=q, \quad b_{1}=1, \\
\sigma_{-1}=0 ; \quad \sigma_{0}=-q ; \quad \sigma_{1}=-\frac{1}{2} u, \\
b_{2}=q, \quad b_{3}=-q_{x}+q^{2}+\frac{1}{2} u, \\
c_{2}=\frac{1}{2} a-2 q q_{x}+q_{x x}-\frac{3}{4} u_{x}, \quad c_{3}=\frac{1}{4} a_{x}-\frac{1}{2} a q-\frac{1}{8} u_{x x}-\frac{1}{8} u^{2}, \\
\sigma_{2}=-\frac{3}{2} a+2 q q_{x}-q_{x x}+\frac{5}{4} u_{x} ; \quad \sigma_{3} a q-\frac{1}{8} u_{x x}-\frac{1}{8} u^{2} ; \\
b_{4}=\frac{1}{2} a-3 q q_{x}+q_{x x}+q u+q^{3}-\frac{3}{4} u_{x}, \\
c_{4}=-\frac{7}{4} a_{x} q+\frac{7}{8} a_{x x}-\frac{9}{4} a q_{x}+\frac{1}{2} a q^{2}+3 q_{x} u_{x}-2 q q_{x} u+ \\
+q_{x x} u-2 q_{x} q^{3}+5 q^{2} q_{x x}+10 q_{x}^{2} q+\frac{1}{2} a u-4 q q_{x x x}+ \\
-9 q_{x} q_{x x}+q_{4 x}-q^{2} u_{x}+2 q u_{x x}-\frac{3}{4} u u_{x}-\frac{15}{16} u_{x x x}, \\
\sigma_{4}=\frac{9}{4} a_{x} q-\frac{9}{8} a_{x x}+\frac{15}{4} a q_{x}-\frac{3}{2} a q^{2}-3 q_{x} u_{x}+2 q_{x} q u+ \\
-q_{x x} u+2 q_{x} q^{3}-5 q_{x x} q^{2}-10 q_{x}^{2} q-\frac{3}{2} a u+4 q q_{x x x}+ \\
+9 q_{x} q_{x x}-q_{4 x}+q^{2} u_{x}-2 q u_{x x}+\frac{5}{4} u u_{x}+\frac{17}{16} u_{x x x} .
\end{gathered}
$$

Thus, taking into account representation (16) we conclude that all the functionals

$$
\gamma_{j}=\partial_{(l)}^{-1}\left(\sigma_{j}[u, a, q]\right)=\int_{x_{0}}^{x_{0}+l} \sigma_{j}[u, a, q] d x, \quad j=0,1, \ldots
$$

are conservation laws for the dynamical system (12), and due to the construction process, they are functionally independent.

Hence, first five nontrivial conservation laws for Eqs. (12) have the following form:

$$
\begin{gathered}
\gamma_{0}=\int_{x_{0}}^{x_{0}+l} q d x ; \quad \gamma_{1}=\int_{x_{0}}^{x_{0}+l} u d x ; \quad \gamma_{2}=\int_{x_{0}}^{x_{0}+l} a d x ; \\
\gamma_{3}=\int_{x_{0}}^{x_{0}+l}\left(4 a q+u^{2}\right) d x ; \quad \gamma_{4}=\int_{x_{0}}^{x_{0}+l} a\left(-q_{x}+q^{2}+u\right) d x .
\end{gathered}
$$

Now let us compute the gradients of the conservation laws (23) which would be useful further on for the Hamiltonian analysis.

$$
\begin{gathered}
\operatorname{grad} \gamma_{0}=(0 ; 0 ; 1)^{\top} ; \\
\operatorname{grad} \gamma_{1}=(1 ; 0 ; 0)^{\top} ; \\
\operatorname{grad} \gamma_{2}=(0 ; 1 ; 0)^{\top} ; \\
\operatorname{grad} \gamma_{3}=(2 u ; 4 q ; 4 a)^{\top} ; \\
\operatorname{grad} \gamma_{4}=\left(a ;-q_{x}+q^{2}+u ; a_{x}+2 a q\right)^{\top} .
\end{gathered}
$$




\subsection{IMPLECTIC OPERATORS}

Having found the infinite hierarchy of conservation laws for the dynamical system (12), we can use it in order to find the implectic pair of Noetherian operators utilizing the differential-algebraic algorithm.

Choose the Hamiltonian functional

$$
H_{\vartheta}=H_{\vartheta}[u, a, q]=-\gamma_{3}[u, a, q]=-\int_{x_{0}}^{x_{0}+l}\left(4 a q+u^{2}\right) d x .
$$

Firstly, we find the representation of the functional (24) in the form

$$
\int_{x_{0}}^{x_{0}+l}\left(\left\langle\bar{\sigma}_{1}[u, a, q], u_{x}\right\rangle+\left\langle\bar{\sigma}_{2}[u, a, q], a_{x}\right\rangle+\left\langle\bar{\sigma}_{3}[u, a, q], q_{x}\right\rangle\right) d x
$$

i.e.

$$
\begin{aligned}
H_{\vartheta} & =-\int_{x_{0}}^{x_{0}+l}\left(4 a q+u^{2}\right) d x=-\int_{x_{0}}^{x_{0}+l}\left(u \partial^{-1} u_{x}+2 q \partial^{-1} a_{x}+2 a \partial^{-1} q_{x}\right) d x= \\
& =\int_{x_{0}}^{x_{0}+l}\left(\left\langle\partial^{-1} u, u_{x}\right\rangle+\left\langle 2 \partial^{-1} q, a_{x}\right\rangle+\left\langle 2 \partial^{-1} a, q_{x}\right\rangle\right) d x
\end{aligned}
$$

Hence, we obtain

$$
\sigma^{\prime}=\left(\begin{array}{lll}
\frac{\partial \bar{\sigma}_{1}}{\partial u} & \frac{\partial \bar{\sigma}_{1}}{\partial a} & \frac{\partial \bar{\sigma}_{1}}{\partial q} \\
\frac{\partial \bar{\sigma}_{2}}{\partial u} & \frac{\partial \bar{\sigma}_{2}}{\partial a} & \frac{\partial \bar{\sigma}_{2}}{\partial q} \\
\frac{\partial \bar{\sigma}_{3}}{\partial u} & \frac{\partial \bar{\sigma}_{3}}{\partial a} & \frac{\partial \bar{\sigma}_{3}}{\partial q}
\end{array}\right)=\left(\begin{array}{ccc}
\partial^{-1} & 0 & 0 \\
0 & 0 & 2 \partial^{-1} \\
0 & 2 \partial^{-1} & 0
\end{array}\right)
$$

and

$$
\sigma^{*}=\left(\begin{array}{ccc}
-\partial^{-1} & 0 & 0 \\
0 & 0 & -2 \partial^{-1} \\
0 & -2 \partial^{-1} & 0
\end{array}\right)
$$

Thus,

$$
\theta_{1}^{-1}=\sigma^{\prime}-\sigma^{*}=\left(\begin{array}{ccc}
2 \partial^{-1} & 0 & 0 \\
0 & 0 & 4 \partial^{-1} \\
0 & 4 \partial^{-1} & 0
\end{array}\right)
$$

Since the inverse of $\theta_{1}^{-1}$ exists, we obtain the first sought-after implectic operator

$$
\eta=\theta_{1}=\left(\begin{array}{ccc}
\frac{1}{2} \partial & 0 & 0 \\
0 & 0 & \frac{1}{4} \partial \\
0 & \frac{1}{4} \partial & 0
\end{array}\right)
$$

Furthermore, from the hamiltonicity condition

$$
\left(\begin{array}{l}
u \\
a \\
q
\end{array}\right)_{t}=-\eta \operatorname{grad} H_{\eta}
$$


we can find the functional $H_{\eta}$, namely

$$
-\left(\begin{array}{ccc}
\frac{1}{2} \partial & 0 & 0 \\
0 & 0 & \frac{1}{4} \partial \\
0 & \frac{1}{4} \partial & 0
\end{array}\right)\left(\begin{array}{c}
\frac{\delta H_{\eta}}{\delta u} \\
\frac{\delta H_{\eta}}{\delta a} \\
\frac{\delta H_{\eta}}{\delta q}
\end{array}\right)=\left(\begin{array}{c}
2 a_{x} \\
\left(a_{x}+2 a q\right)_{x} \\
\left(-q_{x}+q^{2}+u\right)_{x}
\end{array}\right),
$$

which yields

$$
\begin{aligned}
\frac{\delta H_{\eta}}{\delta u} & =-4 a \\
\frac{\delta H_{\eta}}{\delta a} & =-4\left(a_{x}+2 a q\right) \\
\frac{\delta H_{\eta}}{\delta q} & =-4\left(-q_{x}+q^{2}+u\right) .
\end{aligned}
$$

Hence, $\operatorname{grad} H_{\eta}=-4 \operatorname{grad} \gamma_{4}$ which means that

$$
H_{\eta}=-4 \gamma_{4}=-4 \int_{x_{0}}^{x_{0}+l} a\left(-q_{x}+q^{2}+u\right) d x .
$$

Again, let us represent (34) in the form (25), namely

$$
\begin{aligned}
H_{\eta} & =-4 \int_{x_{0}}^{x_{0}+l} a\left(-q_{x}+q^{2}+u\right) d x= \\
& =-\int_{x_{0}}^{x_{0}+l}\left(4 a \partial^{-1} u_{x}+4 q^{2} \partial^{-1} a_{x}-4 a q_{x}\right) d x= \\
& =\int_{x_{0}}^{x_{0}+l}\left(\left\langle 4 \partial^{-1} a, u_{x}\right\rangle+\left\langle 4 \partial^{-1}\left(q^{2}\right), a_{x}\right\rangle+\left\langle 4 a, q_{x}\right\rangle\right) d x .
\end{aligned}
$$

Similarly,

$$
\begin{gathered}
\sigma^{\prime}=\left(\begin{array}{ccc}
0 & 4 \partial^{-1} & 0 \\
0 & 0 & 8 \partial^{-1} q \\
0 & 4 & 0
\end{array}\right), \\
\sigma^{*}=\left(\begin{array}{ccc}
0 & 0 & 0 \\
-4 \partial^{-1} & 0 & 4 \\
0 & -8 q \partial^{-1} & 0
\end{array}\right),
\end{gathered}
$$

and

$$
\theta_{2}^{-1}=\sigma^{\prime}-\sigma^{*}=\left(\begin{array}{ccc}
0 & 4 \partial^{-1} & 0 \\
4 \partial^{-1} & 0 & 8 \partial^{-1} q-4 \\
0 & 4+8 q \partial^{-1} & 0
\end{array}\right) .
$$

Finally, the second sought-after implectic operator $\vartheta$ can be obtained from the equality $\vartheta=\eta \theta_{2}^{-1} \eta$ as follows:

$$
\vartheta=\eta \theta_{2}^{-1} \eta=\left(\begin{array}{ccc}
0 & 0 & \frac{1}{2} \partial \\
0 & 0 & \frac{1}{4} \partial^{2}+\frac{1}{2} q_{x}+\frac{1}{2} q \partial \\
\frac{1}{2} \partial & \frac{1}{2} q \partial-\frac{1}{4} \partial^{2} & 0
\end{array}\right) .
$$


With the direct computation we make sure that the operators $\vartheta$ and $\eta$ are Noetherian, i.e. $\mathcal{L}_{K} \vartheta=\mathcal{L}_{K} \eta=0$. It can be also shown [12] that the pair $(\vartheta, \eta)$ is compatible.

Thus, we have just proven the following

Theorem 1. Dynamical system (12) is bi-Hamiltonian, i.e. it can be represented as

$$
w_{t}=-\vartheta \operatorname{grad} H_{\vartheta}=-\eta \operatorname{grad} H_{\eta}=K[w],
$$

where $H_{\vartheta}, H_{\eta} \in D(M)$ are Hamiltonian functionals given by Eqs. (24), (34), and $\vartheta, \eta$ : $T^{*}(M) \rightarrow T(M)$ is the compatible pair of implectic and Noetherian operators given by Eqs. (39), (30).

\section{ExACT SOLUTiONS}

In this section, we apply the $\left(\frac{G^{\prime}}{G}\right)$ - expansion method to find some classes of particular solutions of Eq. (1).

Step 1. Introducing traveling wave variable $\xi=x-V t$, we reduce the dynamical system (1) to a system of ODEs for $u=u(\xi), a=a(\xi)$ and $q=q(\xi)$ :

$$
\left\{\begin{array}{l}
-V u^{\prime}=2 a^{\prime} \\
-V a^{\prime}=a^{\prime \prime}+2 a^{\prime} q+2 a q^{\prime} \\
-V q^{\prime}=-q^{\prime \prime}+2 q q^{\prime}+u^{\prime}
\end{array} .\right.
$$

At this point, we can integrate all the equations of the system (40) once w.r.t. $\xi$ in order to simplify our further computations:

$$
\left\{\begin{array}{l}
C_{1}-V u-2 a=0 \\
C_{2}-V a-a^{\prime}-2 a q=0 \\
C_{3}-V q+q^{\prime}-q^{2}-u=0
\end{array},\right.
$$

where $C_{1}, C_{2}, C_{3}$ are all arbitrary integration constants.

Suppose that the solution of Eq. (41) can be expressed in terms of polynomials in $\left(\frac{G^{\prime}}{G}\right)$ as follows:

$$
\left\{\begin{array}{l}
u(\xi)=\sum_{i=0}^{k} \alpha_{i}\left(\frac{G^{\prime}}{G}\right)^{i} \\
a(\xi)=\sum_{i=0}^{l} \beta_{i}\left(\frac{G^{\prime}}{G}\right)^{i}, \\
q(\xi)=\sum_{i=0}^{m} \gamma_{i}\left(\frac{G^{\prime}}{G}\right)^{i}
\end{array}\right.
$$

In order to find the degrees $k, l$ and $m$ in Eqs. (42), consider the homogeneous balance between $u$ and $a, a^{\prime}$ and $a q$, and $q^{\prime}$ and $q^{2}$ in the first, the second, and the third equations of (41), respectively. Hence, we obtain the system of algebraic equations

$$
\left\{\begin{array}{l}
k=l \\
l+1=l+m \\
m+1=2 m
\end{array},\right.
$$

from which we obtain that $m=1$ and $k=l=\nu$ - an arbitrary non-negative integer. Note that the classical $\left(\frac{G^{\prime}}{G}\right)$ - expansion method does not tackle this kind of peculiarity 
(all the degrees in Eqs. (42) are assumed to be uniquely determinable from Eqs. (43)). However, we will show further on that in the case of Eq. (40) the solution in the powers of $\left(\frac{G^{\prime}}{G}\right)$ is still unique. form:

Step 2. Considering (42) and (43), we find the solution of Eqs. (41) in the following

$$
\left\{\begin{array}{l}
u(\xi)=\sum_{i=0}^{\nu} \alpha_{i}\left(\frac{G^{\prime}}{G}\right)^{i} \\
a(\xi)=\sum_{i=0}^{\nu} \beta_{i}\left(\frac{G^{\prime}}{G}\right)^{i} \\
q(\xi)=\gamma_{0}+\gamma_{1}\left(\frac{G^{\prime}}{G}\right)
\end{array}\right.
$$

where the function $G=G(\xi)$ satisfies the second order linear ODE

$$
G^{\prime \prime}+\lambda G^{\prime}+\mu G=0
$$

and $\lambda, \mu, V, \alpha_{i}, \beta_{i}(i=\overline{0, \nu}), \gamma_{j}(j=\overline{0,1})$ are all constants to be determined later, $\alpha_{\nu} \neq$ $0, \beta_{\nu} \neq 0, \gamma_{1} \neq 0$.

Step 3. Substituting (44) into the system (41) and collecting all the terms with the same power of $\left(\frac{G^{\prime}}{G}\right)$ together, left-hand sides of equations (41) are converted into other polynomials in $\left(\frac{G^{\prime}}{G}\right)$. Equating each coefficient of these polynomials to zero yields a set of simultaneous algebraic equations for $\lambda, \mu, V, \alpha_{i}, \beta_{i}(i=\overline{0, \nu}), \gamma_{j}(j=\overline{0,1})$.

Now let us prove that the only value of $\nu$ for which the above-mentioned system of algebraic equations has a solution is $\nu=2$. Indeed, for $\nu=0$ we get the following set of simultaneous equations:

$$
\left\{\begin{array}{l}
-2 \beta_{0}+C_{1}-\alpha_{0} V=0 \\
-2 \beta_{0} \gamma_{0}+C_{2}-\beta_{0} V=0 \\
-2 \beta_{0} \gamma_{1}=0 \\
-\alpha_{0}-\gamma_{1} \mu-\gamma_{0}^{2}+C_{3}-\gamma_{0} V=0 \\
-\gamma_{1} \lambda-2 \gamma_{0} \gamma_{1}+\gamma_{1}(-V)=0 \\
-\gamma_{1}^{2}-\gamma_{1}=0
\end{array}\right.
$$

and also restrictions $\alpha_{0} \neq 0, \beta_{0} \neq 0, \gamma_{1} \neq 0$; obviously, the third equation in (46) contradicts the restrictions, and hence Eqs. (46) have no solution.

Furthermore, for $\nu=1$ we obtain the following system of algebraic equations:

$$
\left\{\begin{array}{l}
-2 \beta_{0}+C_{1}-\alpha_{0} V=0 \\
\alpha_{1}(-V)-2 \beta_{1}=0 \\
-2 \beta_{0} \gamma_{0}+\beta_{1} \mu+C_{2}-\beta_{0} V=0 \\
-2 \beta_{1} \gamma_{0}-2 \beta_{0} \gamma_{1}+\beta_{1} \lambda+\beta_{1}(-V)=0 \\
\beta_{1}-2 \beta_{1} \gamma_{1}=0 \\
-\alpha_{0}-\gamma_{1} \mu-\gamma_{0}^{2}+C_{3}-\gamma_{0} V=0 \\
-\alpha_{1}-\gamma_{1} \lambda-2 \gamma_{0} \gamma_{1}-\gamma_{1} V=0 \\
-\gamma_{1}^{2}-\gamma_{1}=0
\end{array}\right.
$$


Mykhailiuk I., Prytula M.

ISSN 2078-5097. Вісн. Львів. ун-ту. Сер. прикл. матем. та інф. 2020. Вип. 28

and also restrictions $\alpha_{1} \neq 0, \beta_{1} \neq 0, \gamma_{1} \neq 0$; again, equations $\beta_{1}-2 \beta_{1} \gamma_{1}=0$ and $-\gamma_{1}^{2}-\gamma_{1}=0$ in Eqs. (47) contradict the restrictions, and therefore Eqs. (47) have no solution.

Now let us show that for the general case $\nu \geq 3$ the above-mentioned system of algebraic equations has no solutions, either. Substituting (44) into the third equation in Eqs. (41), using the identity

$$
\left(\frac{G^{\prime}}{G}\right)^{\prime}=\frac{G^{\prime \prime} G-\left(G^{\prime}\right)^{2}}{G^{2}}=\frac{G^{\prime \prime}}{G}-\left(\frac{G^{\prime}}{G}\right)^{2}=-\mu-\lambda\left(\frac{G^{\prime}}{G}\right)-\left(\frac{G^{\prime}}{G}\right)^{2}
$$

we obtain:

$$
\begin{gathered}
C_{3}-V\left[\gamma_{1}\left(\frac{G^{\prime}}{G}\right)+\gamma_{0}\right]+\gamma_{1}\left[-\mu-\lambda\left(\frac{G^{\prime}}{G}\right)-\left(\frac{G^{\prime}}{G}\right)^{2}\right]+ \\
-\left[\gamma_{1}\left(\frac{G^{\prime}}{G}\right)+\gamma_{0}\right]^{2}-\sum_{i=0}^{\nu} \alpha_{i}\left(\frac{G^{\prime}}{G}\right)^{i}=0,
\end{gathered}
$$

or

$$
\begin{gathered}
C_{3}-V\left[\gamma_{1}\left(\frac{G^{\prime}}{G}\right)+\gamma_{0}\right]+\gamma_{1}\left[-\mu-\lambda\left(\frac{G^{\prime}}{G}\right)-\left(\frac{G^{\prime}}{G}\right)^{2}\right]+ \\
-\left[\gamma_{1}\left(\frac{G^{\prime}}{G}\right)+\gamma_{0}\right]^{2}-\sum_{i=0}^{\nu-1} \alpha_{i}\left(\frac{G^{\prime}}{G}\right)^{i}=\alpha_{\nu}\left(\frac{G^{\prime}}{G}\right)^{\nu} .
\end{gathered}
$$

Since $\nu \geq 3$, the left-hand side of Eq. (50) contains only the terms with $\operatorname{deg}\left(\frac{G^{\prime}}{G}\right) \leq$ $\nu-1$, therefore, $\alpha_{\nu}\left(\frac{G^{\prime}}{G}\right)^{\nu}$ is the only term with $\operatorname{deg}\left(\frac{G^{\prime}}{G}\right)=\nu$ which means that the equation $\alpha_{\nu}=0$ will necessarily be in the above-mentioned system of algebraic equations, and this contradicts the restriction $\alpha_{\nu} \neq 0$.

Hence, the only candidate value of the degree $\nu$ is $\nu=2$. Indeed, in this case we obtain the following set of algebraic equations:

$$
\left\{\begin{array}{l}
-2 \beta_{0}+C_{1}-\alpha_{0} V=0 \\
\alpha_{1}(-V)-2 \beta_{1}=0 \\
\alpha_{2}(-V)-2 \beta_{2}=0 \\
-2 \beta_{0} \gamma_{0}+\beta_{1} \mu+C_{2}-\beta_{0} V=0 \\
-2 \beta_{1} \gamma_{0}-2 \beta_{0} \gamma_{1}+\beta_{1} \lambda+2 \beta_{2} \mu+\beta_{1}(-V)=0 \\
-2 \beta_{1} \gamma_{1}-2 \beta_{2} \gamma_{0}+2 \beta_{2} \lambda+\beta_{1}-\beta_{2} V=0 \\
2 \beta_{2}-2 \beta_{2} \gamma_{1}=0 \\
-\alpha_{0}-\gamma_{1} \mu-\gamma_{0}^{2}+C_{3}-\gamma_{0} V=0 \\
-\alpha_{1}-\gamma_{1} \lambda-2 \gamma_{0} \gamma_{1}-\gamma_{1} V=0 \\
-\alpha_{2}-\gamma_{1}^{2}-\gamma_{1}=0
\end{array}\right.
$$


which, along with the restrictions $\alpha_{2} \neq 0, \beta_{2} \neq 0, \gamma_{1} \neq 0$ yields the solution

$$
\left\{\begin{array}{l}
\alpha_{1}=-2 \lambda, \\
\alpha_{2}=-2, \\
\beta_{0}=\mu V, \\
\beta_{1}=\lambda V, \\
\beta_{2}=V, \\
\gamma_{0}=\frac{\lambda-V}{2}, \\
\gamma_{1}=1, \\
C_{1}=V\left(\alpha_{0}+2 \mu\right), \\
C_{2}=0, \\
C_{3}=\frac{1}{4}\left(4 \alpha_{0}+\lambda^{2}+4 \mu-V^{2}\right),
\end{array}\right.
$$

where $\lambda, \mu, V, \alpha_{0}$ are all arbitrary parameters.

Finally, substituting the obtained solution (52) along with the solutions of the secondorder LODE (45) into (44) enables us to write down three classes of traveling wave solutions of the original Eq. (1) explicitly.

\subsection{Hyperbolic FunCtion (SOlitary WaVe) SOlutions}

If $\lambda^{2}-4 \mu>0$, denoting $\sigma=\lambda^{2}-4 \mu$, we get the family of hyperbolic function solutions

$$
\left\{\begin{array}{l}
u(\xi)=-\frac{\left(A_{1}^{2}-A_{2}^{2}\right) \sigma}{2\left(A_{1} \sinh \frac{\xi \sqrt{\sigma}}{2}+A_{2} \cosh \frac{\xi \sqrt{\sigma}}{2}\right)^{2}}+\alpha_{0}+2 \mu, \\
a(\xi)=\frac{V \sigma\left(A_{1}^{2}-A_{2}^{2}\right)}{4\left(A_{1} \sinh \frac{\xi \sqrt{\sigma}}{2}+A_{2} \cosh \frac{\xi \sqrt{\sigma}}{2}\right)^{2}}, \\
q(\xi)=\frac{\sqrt{\sigma}\left(A_{2} \sinh \frac{\xi \sqrt{\sigma}}{2}+A_{1} \cosh \frac{\xi \sqrt{\sigma}}{2}\right)}{2\left(A_{1} \sinh \frac{\xi \sqrt{\sigma}}{2}+A_{2} \cosh \frac{\xi \sqrt{\sigma}}{2}\right)}-\frac{V}{2}
\end{array}\right.
$$

where $\xi=x-V t$, and $A_{1}, A_{2}, \alpha_{0}, V$ are all arbitrary constants.

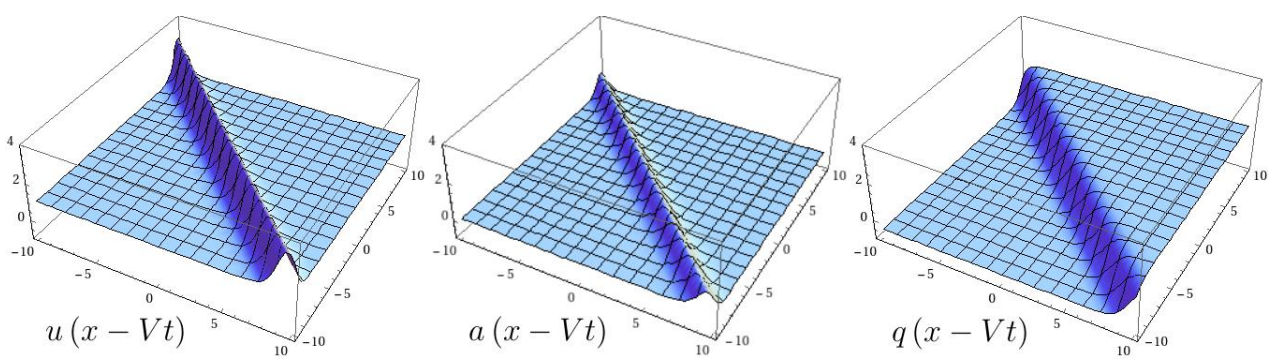

Fig. 1. Hyperbolic solutions (53) for $A_{1}=1, A_{2}=2, \lambda=2.5, \mu=0.5, \alpha_{0}=0, V=-1$

As we can see from Fig. 1, Eqs. (53) under certain choice of arbitrary parameters contain the solitary wave solution of Eq. (1) - localized waves for $u$ and $a$ and kink-like wave for $q$. 


\subsection{RATIONAL FUNCTION SOLUTIONS}

If $\lambda^{2}-4 \mu=0$, denoting again $\sigma=\lambda^{2}-4 \mu$, we get the family of rational function solutions

$$
\left\{\begin{array}{l}
u(\xi)=\frac{A_{2}^{2}\left(\alpha_{0} \xi^{2}+\frac{\lambda^{2} \xi^{2}}{2}-2\right)+A_{2} A_{1} \xi\left(2 \alpha_{0}+\lambda^{2}\right)+A_{1}^{2}\left(\alpha_{0}+\frac{\lambda^{2}}{2}\right)}{\left(A_{2} \xi+A_{1}\right)^{2}} \\
a(\xi)=-V \cdot \frac{A_{2}^{2}\left(\xi^{2} \sigma-4\right)+2 A_{2} A_{1} \xi \sigma+A_{1}^{2} \sigma}{4\left(A_{2} \xi+A_{1}\right)^{2}} \\
q(\xi)=\frac{A_{2}(2-\xi V)-A_{1} V}{2\left(A_{2} \xi+A_{1}\right)}
\end{array}\right.
$$

where $\xi=x-V t$, and $A_{1}, A_{2}, \alpha_{0}, V$ are all arbitrary constants.
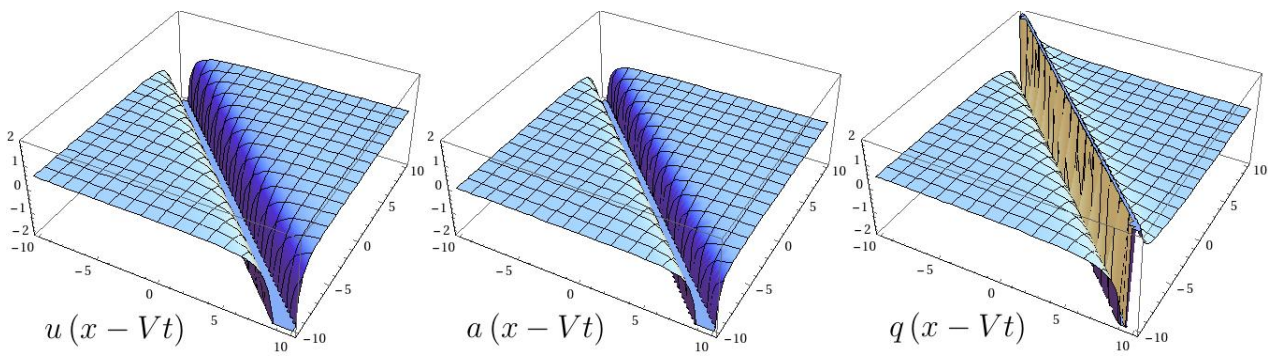

Fig. 2. Rational solutions (54) for $A_{1}=1, A_{2}=2, \lambda=1, \mu=0.25, \alpha_{0}=0, V=-1$

\subsection{TRIGONOMETRIC FUnCTION (PERIODIC) SOLUTIONS}

Finally, if $\lambda^{2}-4 \mu<0$, denoting $\bar{\sigma}=4 \mu-\lambda^{2}$, we get the family of trigonometric function solutions

$$
\left\{\begin{array}{l}
u(\xi)=\frac{-\left(A_{1}^{2}+A_{2}^{2}\right) \bar{\sigma}}{2\left(A_{1} \sin \frac{\xi \sqrt{\sigma}}{2}+A_{2} \cos \frac{\xi \sqrt{\sigma}}{2}\right)^{2}}+2 \mu+\alpha_{0} \\
a(\xi)=\frac{\left(A_{1}^{2}+A_{2}^{2}\right) V \bar{\sigma}}{4\left(A_{1} \sin \frac{\xi \sqrt{\bar{\sigma}}}{2}+A_{2} \cos \frac{\xi \sqrt{\sigma}}{2}\right)^{2}} \\
q(\xi)=\frac{\sqrt{\bar{\sigma}}\left(A_{1} \cos \frac{\xi \sqrt{\bar{\sigma}}}{2}-A_{2} \sin \frac{\xi \sqrt{\bar{\sigma}}}{2}\right)}{2\left(A_{1} \sin \frac{\xi \sqrt{\sigma}}{2}+A_{2} \cos \frac{\xi \sqrt{\sigma}}{2}\right)}-\frac{V}{2}
\end{array}\right.
$$

where $\xi=x-V t$, and $A_{1}, A_{2}, \alpha_{0}, V$ are all arbitrary constants.

As we can see from Fig. 3, Eqs. (55) correspond to the periodic solution of Eq. (1).

Finally, all the obtained solutions have been verified by putting them back into the original Eq. (1).

\section{CONCLUSiON}

For the dispersionful (Burgers' type) nonlinear dynamical system (1) we have constructed the infinite hierarchy of functionally independent conserved densities (integrals of motion) and found its bi-Hamiltonian representation. Essentially, it means that dynamical system (12) is completely integrable (in Liouville sense). However, one might 


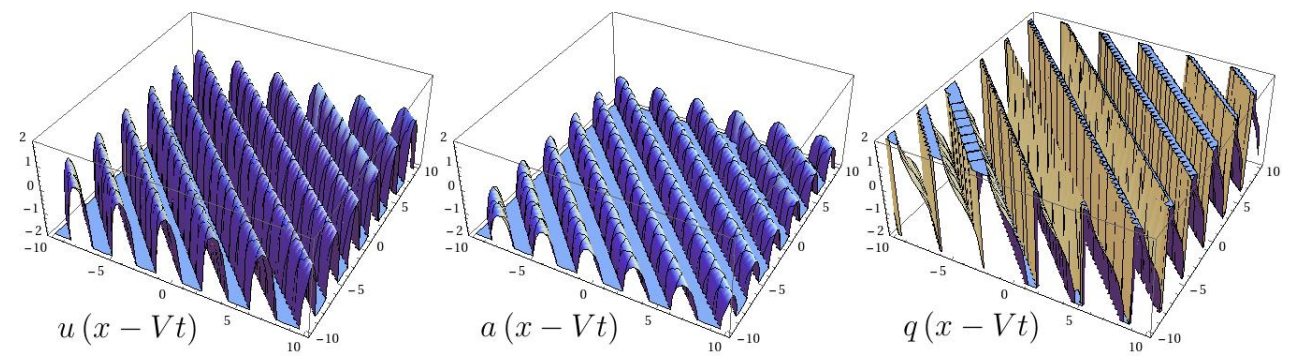

Fig. 3. Trigonometric solutions (55) for $A_{1}=1, A_{2}=2, \lambda=1, \mu=1, \alpha_{0}=0, V=-1$

also want to find the standard Lax type representation [3] of Eq. (12) which makes it possible to actually integrate it by means of the inverse scattering transform method. Apparently, the Lax type representation of Eq. (12) would be an objective of our further research.

On the other hand, we have found three classes of particular exact solutions of Eq. (12). It was shown that all these solutions feature a number of arbitrary parameters which might be of interest for modeling purposes. Moreover, the obtained solutions were verified by putting them back into the original Eq. (1).

Finally, we have used Wolfram Mathematica software to implement the $\left(\frac{G^{\prime}}{G}\right)$ - expansion algorithm and facilitate certain steps of the conservation laws construction process.

\section{REFERENCES}

1. Arnold V. Mathematical Methods of Classical Mechanics / V. Arnold.- New-York: Springer, $1989 .-520 \mathrm{p}$.

2. Fan E. Extended tanh-function method and its applications to nonlinear equations / E. Fan // Phys. Lett. A. - 2000. - No 277. - P. 212-218.

3. Hentosh O. Y. Differential-Geometric and Lie-Algebraic Foundations of Investigating Nonlinear Dynamical Systems on Functional Manifolds / O. Y. Hentosh, M. M. Prytula, A. K. Prykarpatskyi. - Lviv: Publishing center of the Ivan Franko National University of Lviv, 2006.408 p. (In Ukrainian).

4. Hirota R. Direct Methods in Soliton Theory / R. Hirota//Solitons. Topics in Current Physics.- Vol. 17 / ed. by R. Bullough, C. P. - Berlin, Heidelberg: Springer, 1980.- P. 157176.

5. Hitchin N. Integrable Systems: Twistors, Loop Groups, and Riemann Surfaces / N. Hitchin, G. Segal, R. Ward. - Clarendon Press, 1999.- 152 p.

6. Mitropolskiy Y. Integrable dynamical systems: spectral and differential geometric aspects / Y. Mitropolskiy, N. Bogoliubov, A. Prikarpatskiy, V. Samoilenko. - Kyiv: Naukova dumka, 1987. - P. 296.

7. LiuS. Jacobi elliptic function expansion method and periodic wave solutions of nonlinear wave equations / S. Liu, Z. Fu, S. Liu, Q. Zhao // Phys. Lett. A. - 2001. - No 289. - P. 69-74.

8. Kindybaliuk A. Bihamiltonity and exact solutions of Burger's type generalized dynamical system / A. Kindybaliuk, M. Prytula //Visnyk of Lviv University. Series Mechanics and Mathematics. - 2011. - № 74. - P. 109-121.

9. Lax P. Integrals of nonlinear equations and solitary waves / P. Lax // Comm. Pure Appl. Math. - 1968. - No 21. - P. 467-490. 
Mykhailiuk I., Prytula M.

ISSN 2078-5097. Вісн. Львів. ун-ту. Сер. прикл. матем. та інф. 2020. Вип. 28

10. MagriF. A simple model of the integrable Hamiltonian equation / F. Magri // J. Math. Phys. - 1978. - No 19. - P. 1156.

11. Gardner C. Method for Solving the Korteweg - de Vries Equation / C. Gardner, J. Greene, M. Kruskal, R. Miura // Phys. Rev. Lett. - 1967. - № 19.- P. 1095-1097.

12. Prykarpatskyi A. Algebraic aspects of integrability of nonlinear dynamical systems on manifolds / A. Prykarpatskyi, I. Mykytiuk. - Kyiv: Naukova dumka, 1991.- 288 p.

13. Szablikowski B. Dispersionful analog of the Whitham hierarchy / B. Szablikowski, M. Blaszak // Journal of Mathematical Physics. - 2008. - No 49 (8). - P. 21.

14. Szablikowski B. Geometric aspects of integrable systems / B. Szablikowski.- 2008.- P. 159. - Mode of access https://pdfs.semanticscholar.org/8cb9/c196d2717bc40626152bdfb6eb09c60a87cc.pdf

15. Ablowitz $M$. The Inverse Scattering Transform - Fourier Analysis for Nonlinear Problems / M. Ablowitz, D. Kaup, A. Newel, H. Segur // Stud. App. Math. - 1974. - № 4. - P. 249-315.

16. NovikovS. Theory of Solitons: The Inverse Scattering Method / S. Novikov, S. Manakov, L. Pitaevskii, V.Zakharov. - Monographs in Contemporary Mathematics. - Springer US, 1984. - Mode of access https://books.google.com.ua/books?id=Gtv0vY3OObsC.

17. Wang $M$. Solitary wave solutions for variant Boussinesq equations / M. Wang // Phys. Lett. A. - 1995. - № 199. - P. 169-172.

18. Wang $M$. The $\left(G^{\prime} / G\right)$-expansion method and travelling wave solutions of nonlinear evolution equations in mathematical physics / M. Wang, X. Li, J. Zhang // Physics Letters A.2008. - No 372. - P. 417-423.

19. Weiss J. The Painleve property for partial differential equations / J. Weiss, M. Tabor, G. Carnevale // J. Math. Phys. - 1983. - No 24. - P. 522-526.

20. Zabusky N. Interaction of "Solitons" in a Collisionless plasma and the Recurrence of initial states / N. Zabusky, M. Kruskal // Physical Review Letters. - 1965. - Vol. 15, No 6. - P. 240243.

Article: received 13.07.2020

revised 05.10 .2020

printing adoption 07.10 .2020

\title{
БІГАМІЛЬТОНОВІСТЬ І ТОЧНІ РОЗВ'ЯЗКИ ОДНІЕЇ НЕЛІНІЙНОЇ ДИНАМІЧНОЇ СИСТЕМИ ТИПУ БЮРГЕРСА
}

\author{
I. Михайлюк ${ }^{1}$ М. Притула ${ }^{2}$ \\ Львівсъкий начіональний університет імені Івана Франка, \\ вул. Університесъка, 1, Лъвів, 79000, \\ e-mail: ${ }^{1}$ iv.mykh@gmail.com, ${ }^{2}$ mykola.prytula@gmail.com
}

\begin{abstract}
Бігамільтонові системи відіграють важливу роль у вивченні повністю інтегровних нелінійних динамічних систем. Знайдено бігамільтонове представлення та три класи точних розв'язків для однієї трикомпонентної нелінійної динамічної системи типу Бюргерса, яка постає в контексті дисперсійної версії так званої універсальної ієрархії Уізема. На початку наведено деякі важливі означення з теорії повністю інтегровних нелінійних динамічних систем, а саме закону збереження і його градієнта, а також бігамільтонового представлення системи. Далі, для згаданої динамічної системи, побудовано нескінченну ієрархію функціонально незалежних законів збереження за допомогою градієнтно-голономного методу. На підставі цієі ієрархії знайдено пару імплектичних ньотерових операторів і відповідні гамільтоніани з застосуванням диференціально-алгебричного алгоритму. Крім того, побудовано три класи точних розв'язків у вигляді біжучих хвиль, зокрема періодичний та у вигляді усамітненої хвилі, з використанням методу $\left(\mathrm{G}^{\prime} / \mathrm{G}\right)$-розвинення. Доведено, що для розглядуваної динамічної системи у методі $\left(G^{\prime} / G\right)$-розвинення степені многочленів від $\left(G^{\prime} / G\right)$ не
\end{abstract}


Mykhailiuk I., Prytula $M$.

визначаються однозначно з системи алгебричних рівнянь однорідного балансу. Тим не менше, за допомогою детальнішого аналізу загальний вигляд розв'язків знайдено однозначно. Отримані результати проаналізовано, зокрема перевірено правильність аналітичних розв'язків прямою підстановкою в початкові рівняння. Нарешті, розглянуто можливі шляхи подальших досліджень, зокрема пошук стандартного представлення типу Лакса для згаданої динамічної системи.

Ключові слова: нелінійна динамічна система, закон збереження, імплектичний оператор, гамільтоніан, точний розв'язок, усамітнена хвиля, градієнтно-голономний метод, метод (G'/G)-розвинення. 